\section{JTI}

JOURNAL OF

TRAUMA AND INJURY
Received: September 17, 2020 Revised: September 24, 2020 Accepted: September 24, 2020

\section{Correspondence to}

Chan Yong Park, M.D., Ph.D. Department of Trauma Surgery, Wonkwang University Hospital, $895 \mathrm{Mu}$ -

wang-ro, Iksan, 54538, Korea

Tel: +82-63-859-1188

Fax: +82-63-858-3922

E-mail:wkafyddl@hanmail.net

\title{
Merit of Zone III Resuscitative Endo- vascular Occlusion of the Aorta under Real-Time Fluoroscopy in Hybrid ER: A Case of REBOA in Traumatic Cardiac Arrest
}

\author{
Sung Do Lee, M.D. ${ }^{1}$, Seungwoo Chung, M.D. ${ }^{2}$, Young Jun Ki, M.D. ${ }^{3}$, \\ Sang Hyun Seo, M.D. ${ }^{4}$, Chan Yong Park, M.D., Ph.D. ${ }^{5,6}$ \\ ${ }^{1}$ Department of Emergency Medicine, Wonkwang University Hospital Regional Trauma \\ Center, Iksan, Korea \\ ${ }^{2}$ Department of Surgery, Hanyang University Hanmaeum Changwon Hospital, Changwon, \\ Korea \\ ${ }^{3}$ Division of Acute Care Surgery, Department of Surgery, Asan Medical Center, University \\ of Ulsan College of Medicine, Seoul, Korea \\ ${ }^{4}$ Department of Radiology, Wonkwang University Hospital Regional Trauma Center, \\ Iksan, Korea \\ ${ }^{5}$ Department of Trauma Surgery, Wonkwang University Hospital, Iksan, Korea \\ ${ }^{6}$ Department of Traumatology, Wonkwang University College of Medicine, Iksan, Korea
}

Resuscitative endovascular balloon occlusion of the aorta (REBOA) is a novel technique to maintain proximal arterial pressure. It is important to locate the balloon catheter correctly in performing REBOA but it is inaccurate to check the catheter position by external measurement. Even if the position of the catheter is initially confirmed by X-ray, it is difficult to determine the location of the catheter that changes according to various situations. We performed REBOA under real-time fluoroscopy and could maintain the catheter in correct position under various situations.

Keywords: REBOA; Catheters; Position; Fluoroscopy

(http://creativecommons.org/licenses/by-nc/4.0/) which permits unrestricted noncommercial use, distribution, and reproduction in any medium, provided the original work is properly cited. 


\section{JTI}

\section{INTRODUCTION}

Resuscitative endovascular balloon occlusion of the aorta (REBOA) can be useful for temporary hemorrhage control as a bridge technique to definitive hemostasis. REBOA can maintain proximal arterial pressure, but it causes organ ischemia due to aortic occlusion [1-3]. In order to reduce these complications, it is important to position the catheter balloon correctly, but it is currently difficult to accurately confirm the location of the catheter balloon in most trauma bays. REBOA under real-time fluoroscopy in hybrid ER for a patient with traumatic cardiac arrest has not yet been reported in the English literature.

\section{CASE REPORT}

A 50-year-old male visited the emergency room after falling from a height of $14 \mathrm{~m}$. Upon arrival at the emergency room, the patient was in cardiac arrest and returned of spontaneous circulation after 2 minutes of cardiopulmonary resuscitation. The patient's blood pressure was $64 / 42 \mathrm{mmHg}$. In the arterial blood gas analysis test, $\mathrm{PH}$ value was 6.99 and hemoglobin was $4.9 \mathrm{~g} / \mathrm{dL}$.

Computed tomography taken in a previous hospital showed unstable pelvic bone fracture, 5th lumbar spine compression fracture and multiple extravasation in the both internal iliac arteries. In addition, multiple extrava-
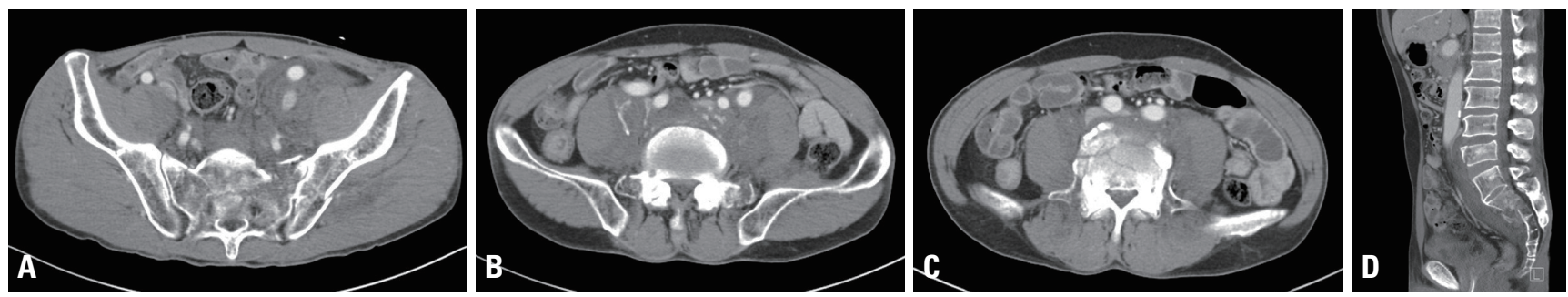

Fig. 1. Abdomen computed tomography taken in a previous hospital showed (A) unstable pelvic bone fracture, (B) active bleeding from psoas muscle, (C) 5th lumbar spine compression fracture (axial view), (D) 5th lumbar spine compression fracture (sagittal view).
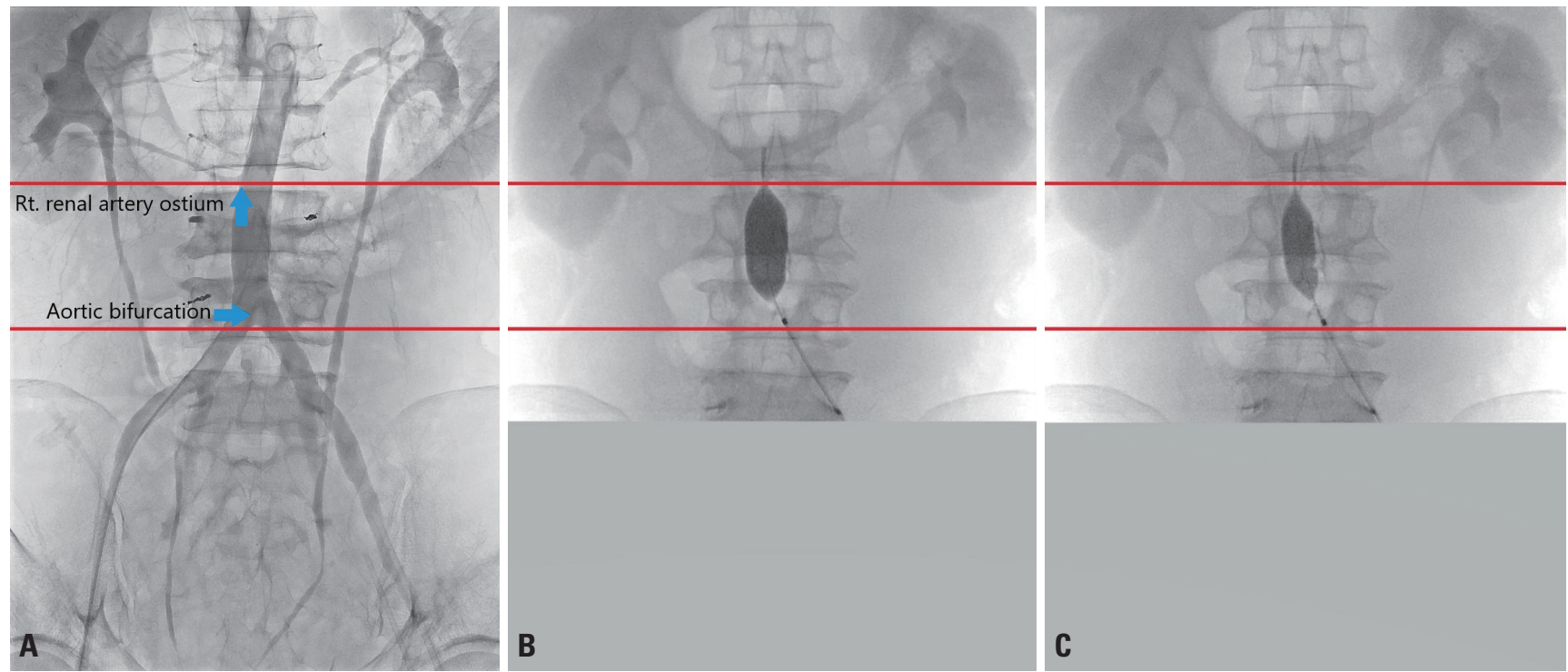

Fig. 2. These are fluoroscopy images of REBOA and Zone III is marked with two red lines. The length of Zone III was $7.5 \mathrm{~cm}$ in this patient, and the length of fully inflated balloon was $5.5 \mathrm{~cm}$. We could locate balloon catheter in Zone III correctly under real-time fluoroscopy. (A) Aortic Zone III (from lowest renal artery to aortic bifurcation). (B) Fully inflated balloon catheter. (C) Partially inflated balloon catheter. 
sation in the both psoas muscle was noted (Fig. 1).

Fluid resuscitation and transfusion were performed, but the patient's blood pressure was not recovered. We inserted a balloon catheter through the left common femoral artery and located the catheter in Zone III (Fig. 2). We maintained total occlusion for the first 3 minutes, then performed angioemolization alternately between patial inflation and total deflation under real-time fluoroscopy according to the patient's blood pressure and other situations.

First, for both internal iliac arterial bleeding, embolization was performed as the concept of damage control interventional radiology (Fig. 3). However, since the patient's blood pressure was not stabilized, additional embolization was performed on the bleeding of multiple lumbar arteries.

After the procedure, the patient's blood pressure was recovered to $96 / 67 \mathrm{mmHg}$ and hemoglobin level returned to $10.6 \mathrm{~g} / \mathrm{dL}$ by emergency transfusion and the patient was admitted to the trauma intensive care unit. The patient underwent two orthopedic surgeries during the hospitalization period and was discharged without any complication dew to ischemic injury 72 days after hospitalization.

\section{DISCUSSION}

REBOA is a novel device approved by the Food and Drug
Administration (FDA) in 2017 as an alternative to resuscitative thoracotomy [4]. It is very effective to get proximal arterial pressure but distal ischemia is one of main complications. So most of the REBOA guidelines recommend that REBOA should be placed at Zones I and III, depending on the location of the hemorrhage or hemodynamic status [5-7] and placement at Zone II should be always avoided for preservation of gastrointestinal perfusion [8].

Although the position of the balloon is important, it is not easy to inflate at the exact position when REBOA is performed with blind technique using external measurement. And there is a study that showed that the accuracy of the position was $12.5 \%$ when REBOA was performed targeting Zone III with blind technique [9].

In this case, the length of Zone III was $7.5 \mathrm{~cm}$. We used a 7-French aortic occlusion catheter (RESCUE BALLOON ${ }^{\circledR}$, Tokai Medical Products, Aichi, Japan) and when the balloon was fully inflated, the length was $5.5 \mathrm{~cm}$. Since the length of Zone III is not that long compared to the length of the balloon, it would have been difficult to accurately position the balloon through external measurement. We were able to stably maintain the correct position of the balloon in various situations under real-time fluoroscopy. In this case, even if the balloon was located on the $1 \mathrm{~cm}$ proximal side, the ostium of the right renal artery could be blocked, causing ischemic injury.

As in this case, when REBOA is performed under real-time fluoroscopy, we can confirm the correct position
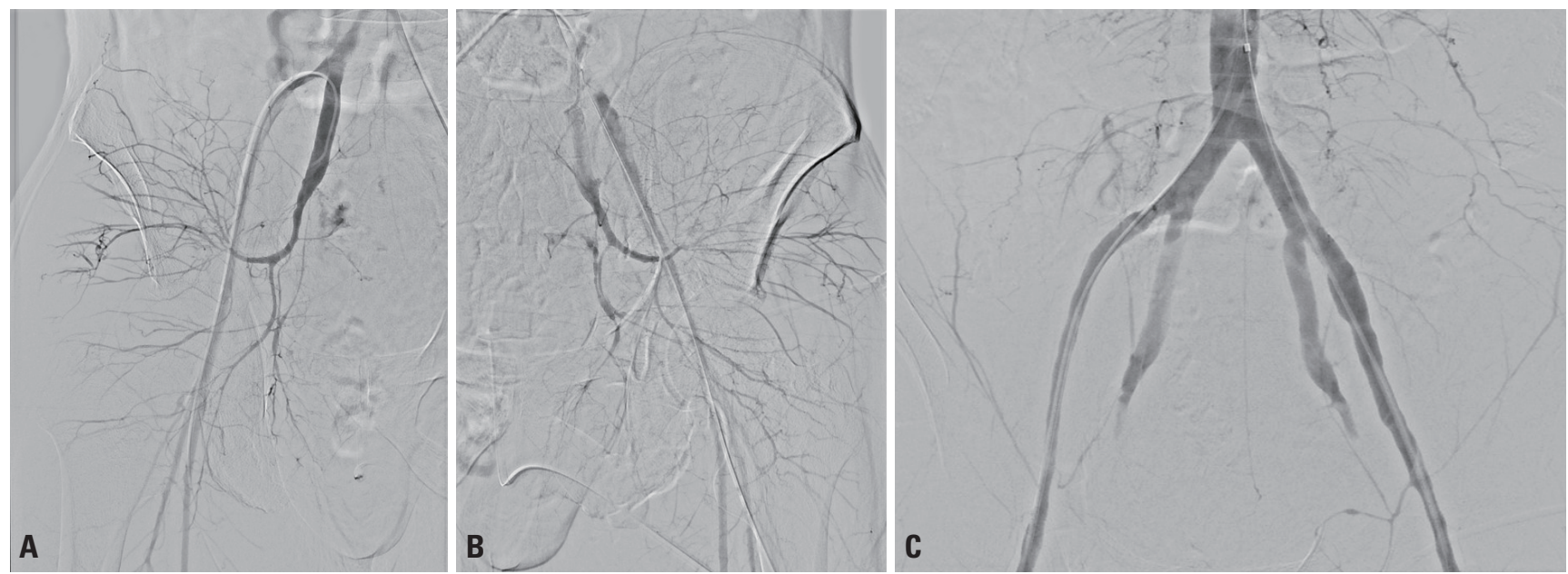

Fig. 3. Angiography under real-time fluoroscopy showed the following findings. (A) Active bleeding from the right internal iliac artery, (B) active bleeding from the left internal iliac artery, (C) follow up angiography after embolization. 
of catheter balloon. The location of the balloon can be changed depending on the blood pressure applied to the balloon or the frictional force between the balloon and the aorta. Under real-time fluoroscopy, the location of the balloon (especially Zone III) can be positioned exactly where it is intended.

In severely injured patients, REBOA under real-time fluoroscopy has not been widely used. In patients who need REBOA, building a system that can check the position of the balloon in real time under real-time fluoroscopy is thought to be helpful for patient resuscitation.

\section{REFERENCES}

1. Ribeiro Junior MAF, Feng CYD, Nguyen ATM, Rodrigues VC, Bechara GEK, de-Moura RR, et al. The complications associated with resuscitative endovascular balloon occlusion of the aorta (REBOA). World J Emerg Surg 2018;13:20.

2. Hoehn MR, Hansraj NZ, Pasley AM, Brenner M, Cox SR, Pasley JD, et al. Resuscitative endovascular balloon occlusion of the aorta for non-traumatic intra-abdominal hemorrhage. Eur J Trauma Emerg Surg 2019;45:713-8.

3. Arndt L, Mir D, Nguyen J, Nezami N, Dariushnia SR, Findeiss LK, et al. The resuscitative endovascular balloon occlusion of aorta (REBOA) device-what radiologists need to know. Emerg Radiol 2019;26:691-4.

4. Moore LJ, Brenner M, Kozar RA, Pasley J, Wade CE, Baraniuk
MS, et al. Implementation of resuscitative endovascular balloon occlusion of the aorta as an alternative to resuscitative thoracotomy for noncompressible truncal hemorrhage. J Trauma Acute Care Surg 2015;79:523-30; discussion 530-2.

5. Brenner M, Bulger EM, Perina DG, Henry S, Kang CS, Rotondo MF, et al. Joint statement from the American College of Surgeons Committee on Trauma (ACS COT) and the American College of Emergency Physicians (ACEP) regarding the clinical use of resuscitative endovascular balloon occlusion of the aorta (REBOA). Trauma Surg Acute Care Open 2018;3:e000154.

6. Zenoni S, Ibrahim J. Resuscitative endovascular balloon occlusion of the aorta (REBOA) [Internet]. Orlando: SurgicalCriticalCare 2018 [cited 2020 Sep 12]. Available from: http://www. surgicalcriticalcare.net/Guidelines/REBOA\%202018.pdf.

7. Pasley JCJ, Glaser J, Polk T, Morrison J, Brocker J, Mitchell B, et al. Joint trauma system clinical practice guideline (JTS CPG): resuscitative endovascular balloon occlusion of the aorta (REBOA) for hemorrhagic shock (CPG ID: 38) [Internet]. San Antonio: Joint Trauma System 2017 [cited 2020 Sep 12]. Available from: http://prytimemedical.com/wp-content/uploads/2017/07/REBOA_-CPG_FINAL.pdf.

8. Stannard A, Eliason JL, Rasmussen TE. Resuscitative endovascular balloon occlusion of the aorta (REBOA) as an adjunct for hemorrhagic shock. J Trauma 2011;71:1869-72.

9. Matsumoto S, Funabiki T, Kazamaki T, Orita T, Sekine K, Yamazaki M, et al. Placement accuracy of resuscitative endovascular occlusion balloon into the target zone with external measurement. Trauma Surg Acute Care Open 2020;5:e00443. 